\title{
Induced Nonradiative Transitions in Benzene
}

\author{
J. W. EASTMAN \\ Institut für Physikalische Chemie der Universität Mainz \\ (Z. Naturforsch. 25 a, 946-955 [1970] ; received 24 February 1970)
}

\begin{abstract}
A nonradiative electronic transition in benzene occurs at about $2400 \mathrm{~cm}^{-1}$ above the zero-point vibration of the ${ }^{1} \mathrm{~B}_{2 \mathrm{u}}$ electronic state. The rate-determining step may be the vibrational relaxation of the product or the nonradiative transition itself. The rate of the latter is limited to $10^{8}<k_{\mathrm{AC}}$ $<10^{11} \mathrm{sec}^{-1}$ in the vapor at 100 torr and $k_{\mathrm{AC}} \sim 10^{12} \mathrm{sec}^{-1}$ in liquids. There are also limiting values in liquids for the threshold energy and the rate of vibrational relaxation of the initial state.

In liquid solutions, the observed transition rate increases with increasing intermolecular force, but it is not increased by alkyl substitutions. Symmetry perturbation and other sources of solventinduced transitions are discussed. Also, means are suggested by which it may be possible to catalyse the formation of benzvalene.
\end{abstract}

\section{Introduction}

Two nonradiative transitions from the ${ }^{1} \mathrm{~B}_{2 \mathrm{u}}$ electronic state of benzene have received attention. The first $\left(\right.$ rate $k_{1}$ ) dominates in the gas state when the excitation wavenumber is below $40,000 \mathrm{~cm}^{-1}$ and in liquid or glassy solutions below $200{ }^{\circ} \mathrm{K}^{1-4}$. This is an intersystem crossing that originates near the zero-point vibrational level ${ }^{5}$, probably occurs in the isolated molecule ${ }^{6,7}$, and is not obviously sensitive to changes of intermolecular forces ${ }^{1-7}$. The second transition $\left(k_{2}\right)$ dominates in the gas state with excitation just above $40,000 \mathrm{~cm}^{-1}$ and in liquids above $300{ }^{\circ} \mathrm{K}^{8-11}$. The two processes are related to the fluorescence quantum yield $q$, the spontaneous emission rate $k_{0}$, and the total nonradiative decay (rate $\left.\sum_{i} k_{i}\right)$ by

$$
\left(\frac{1-q}{q}\right) k_{0}=\sum_{i} k_{i} \cong k_{1}+k_{2},
$$

Reprints request to Dr. J. W. EASTMAN, Shell Development Company, A Division of Shell Oil Company, 1400-53rd Street, Emeryville, California 94 608, USA.

1 H. E. Gilmore, G. E. Gibson, and D. S. McClure, J. Chem. Phys. 20, 829 [1952]; 23, 399 [1955].

2 E. C. Lim, J. Chem. Phys. 36, 3497 [1962].

3 S. Ho and W. A. Noyes, JR., J. Amer. Chem. Soc. 89, 5091 [1967].

4 H. O. Denschlag and E. K. C. Lee, J. Amer. Chem. Soc. 90, 3628 [1968].

5 R. B. Cundall and A. S. Davies, Trans. Faraday Soc. 62 , 1151 [1966].

6 C. S. Parmenter and A. H. White, J. Chem. Phys. 50, 1631 [1969].

7 E. M. Anderson and G. B. Kistiakowsky, J. Chem. Phys. 51,182 [1969].

8 W. A. Noyes, JR., W. A. Mulac, and D. A. Harter, J. Chem. Phys. 44, 2100 [1966].

9 W. A. Noyes, Jr., and D. A. Harter, J. Chem. Phys. 46, 674 [1967]. although the second equality has yet to be demonstrated quantitatively. (We consider only transitions that occur below $42,000 \mathrm{~cm}^{-1}$ in the gas state.)

In liquid solutions at a given temperature the total rate of nonradiative decay increases regularly with increasing electrostatic- and London-interactions between benzene and the solvent ${ }^{12,13}$. At $25^{\circ} \mathrm{C} k_{2}$ constitutes over $70 \%$ of the total ${ }^{10,12}$, and an approximation with a single Arrhenius exponential gives

$$
k_{2}=k_{2}{ }^{0} e^{-E_{2} / k T}
$$

where $k_{2}{ }^{0}=10^{11}-10^{13} \sec ^{-1}$ and ${ }^{14} E_{2} / h c=2400$ $\mathrm{cm}^{-1}$. In the present report the author compares a few mechanisms for the effects that intermolecular forces may have on the second process (on $k_{2}{ }^{0}$ or $E_{2}$ ). The basic theory is given by RoBinson ${ }^{15}$ and BuRland and Robinson ${ }^{16}$. Some of the relevant data are summarized in Table 1 and Fig. 1.

10 J. W. Eastman, J. Chem. Phys. 49, 4617 [1968].

11 W. P. Helman, J. Chem. Phys. 51, 354 [1969].

12 J. W. Eastman and S. J. Rehreld, J. Phys. Chem. 74, 1438 [1970].

13 Nonradiative transitions that populate the ${ }^{1} \mathrm{~B}_{2 u}$ state after excitation at $1849 \mathrm{~A}$ also have a rate that increases with increasing intermolecular forces. C. W. LAwson, F. HirAYAMA, and S. Lipsky, J. Chem. Phys. 51, 1590 [1969].

14 Because the temperature coefficients measured in mixed solvents are complicated by temperature-dependent changes of solvent structure, the activation energy $E_{2}$ adoped here is the one measured in pure liquid solvents, i. e., n-hexane and methanol ${ }^{10}$, and cyclohexane and benzene ${ }^{11}$. Note: If the true values for $E_{2}$ in n-hexane and in methanol were to differ by as much as the precision of the $E_{2}$ measurements $(5-10 \%)$, the ratio of the nonradiative decay rates in these two solvents (a factor of two) would just be accounted for. 15 G. W. Robinson, J. Chem. Phys. 47, 1967 [1967].

16 D. M. Burland and G. W. Robinson, J. Chem. Phys. 51, 4548 [1969]. 


\begin{tabular}{|c|c|c|c|c|c|}
\hline & Solvent ${ }^{\mathrm{a}}$ & Symbol b $^{b}$ & $\begin{array}{c}\text { Fluorescence } \\
\text { Yield } \\
q \text { at } 25^{\circ} \mathrm{C} \text { a }\end{array}$ & $\begin{array}{c}\text { Nonradiative } \\
\text { Decay } \\
10^{-8} \sum_{i} k_{i}\end{array}$ & $\begin{array}{c}\text { Cohesive } \\
\text { Energy } \\
\text { Density, } \\
\delta^{2} \frac{(\mathrm{cal}) \mathrm{c}}{\left(\mathrm{cm}^{3}\right)}\end{array}$ \\
\hline 1) & Vapor $(>10$ torr $)$ & - & $0-0.18$ & $\begin{array}{l}>0.11^{\mathrm{d}} \\
<0.6\end{array}$ & 0 \\
\hline 2) & 2-Methylbutane & 0 & 0.044 & 0.54 & 46 \\
\hline 3) & 2,2,4-Trimethylpentane & 0 & 0.057 & 0.41 & 48 \\
\hline 4) & n-Pentane & 0 & 0.054 & 0.44 & 50 \\
\hline 5) & n-Hexane & 0 & 0.058 & 0.41 & 54 \\
\hline 6) & n-Octane & 0 & 0.057 & 0.41 & 58 \\
\hline 7) & n-Nonane & 0 & 0.059 & 0.40 & 60 \\
\hline 8) & Methylcyclohexane & 0 & 0.046 & 0.52 & 62 \\
\hline 9) & n-Hexadecane & 0 & 0.063 & 0.37 & 67 \\
\hline 10) & Cyclopentane & 0 & 0.056 & 0.42 & 66 \\
\hline 11) & Cyclohexane & 0 & 0.061 & 0.38 & 68 \\
\hline 14) & Tetramethylsilane & 0 & 0.054 & 0.44 & 38 \\
\hline 15) & 3-Methyl-1-Butanol & $\otimes$ & 0.045 & 0.53 & 100 \\
\hline 16) & 2-Methyl-2-Propanol & $\otimes$ & 0.031 & 0.78 & 113 \\
\hline 18) & 2-Methyl-1-Propanol & $\otimes$ & 0.042 & 0.57 & 112 \\
\hline 19) & 1-Butanol & $\otimes$ & 0.045 & 0.53 & 120 \\
\hline 20) & 2-Propanol & $\otimes$ & 0.037 & 0.65 & 132 \\
\hline 22) & Ethanol & $\otimes$ & 0.033 & 0.73 & 168 \\
\hline 23$)$ & Diethylether & $\triangle$ & 0.047 & 0.51 & 60 \\
\hline 25) & 1,2-Propanediol & $\otimes$ & 0.029 & 0.84 & 196 \\
\hline 26) & 1,2-Ethanediol & $\otimes$ & 0.029 & 0.84 & 212 \\
\hline 27) & Methanol & $\otimes$ & 0.027 & 0.90 & 212 \\
\hline 29) & 1,2-Dichloroethane & $\square$ & 0.031 & 0.78 & 100 \\
\hline 30$)$ & Dichloromethane & $\square$ & 0.031 & 0.78 & 99 \\
\hline 32$)$ & 1,4-Dioxane & $\triangle$ & 0.044 & 0.54 & 96 \\
\hline 34$)$ & 1,2,3-Propanetriol & $\otimes$ & 0.025 & 0.98 & 272 \\
\hline 36$)$ & Acetonitrile & $\diamond$ & 0.029 & 0.84 & 141 \\
\hline 37$)$ & Chloroform & $\square$ & 0.005 & $5.1 \mathrm{e}$ & 87 \\
\hline 39$)$ & Water & $\otimes$ & 0.006 & 4.3 & 552 \\
\hline 40) & $\mathrm{D}_{2} \mathrm{O}$ & $\otimes$ & 0.005 & 5.0 & 568 \\
\hline
\end{tabular}

a See Ref. ${ }^{12}$.

b Figures 3 and 5 .

c From Ref. ${ }^{38}$. Also G. Allen, G. Gee, and G. J. Wilson, Polymer 1, 456 [1960] ; and H. Burrell, Interchem. Rev. 14, 31 [1955]. d Hypothetical limits only for a vapor with two vibrational levels in equilibrium; $\sum_{i} k_{i}=\left\{\sum_{i \neq 2} k_{i}+k_{2}{ }^{0} e^{-E_{2} / k T}\right\}$ with
$\sum_{i \neq 2} k_{i}=0.11 \times 10^{8} \mathrm{sec}^{-1}, E_{2} / h c=1600 \mathrm{~cm}^{-1}$, and $10^{8}<k_{2}{ }^{0}<10^{11} \sec ^{-1}$.

e If all molecules of the dissolved benzene were equivalent (see Ref. ${ }^{40}$ ).

Table 1. The fluorescence yield of benzene dissolved in liquids. Key to Figs. 3 and 5 .

\begin{tabular}{|c|c|c|c|c|c|}
\hline $\begin{array}{l}\text { Nuclear } \\
\text { Coupling } \\
\text { Coordinate }\end{array}$ & $\begin{array}{c}\text { Idealized } \\
\text { Rate-Determining } \\
\text { Step }\end{array}$ & $\begin{array}{l}\text { Irrevers- } \\
\text { ibility }\end{array}$ & $\begin{array}{l}\text { Potential } \\
\text { Energy } \\
\text { Surfaces }\end{array}$ & $\begin{array}{c}\text { Electronic } \\
\text { Energy } \\
\text { Converted } \\
(\Delta E) \\
\end{array}$ & $\begin{array}{l}\text { Anticipated } \\
\text { Solvent } \\
\text { Effect on: }\end{array}$ \\
\hline \multirow{2}{*}{$\begin{array}{l}\text { Inter- } \\
\text { molecular }\end{array}$} & $\begin{array}{l}\text { I. Vibrational } \\
\text { Relaxation }\end{array}$ & $k_{\mathrm{no}}^{\prime}>k_{\mathrm{ro}}^{\prime}$ & - & - & $k_{2}^{0}=k=k_{\mathrm{no}}^{\prime}$ \\
\hline & $\begin{array}{l}\text { IIA. Nonradiative } \\
\text { Transition }\end{array}$ & $\varrho_{\mathrm{ac}}>\varrho_{\mathrm{ca}}$ & - & - & $k_{2}^{0}=k=k_{\mathrm{AC}}$ \\
\hline \multirow{2}{*}{$\begin{array}{l}\text { Intra- } \\
\text { molecular }\end{array}$} & \multirow{2}{*}{$\begin{array}{l}\text { IIB. Nonradiative } \\
\text { Transition }\end{array}$} & \multirow{2}{*}{$\varrho_{\mathrm{ac}}>\varrho_{\mathrm{ca}}$} & Cross & $\left.\begin{array}{l}\text { Small or } \\
\text { Large }\end{array}\right\}$ & $\begin{aligned} k_{2}^{0} & =k=k_{\mathrm{AC}}[\beta] \\
E_{2} & =E_{\mathrm{A}}\end{aligned}$ \\
\hline & & & Nested & $\begin{array}{l}\text { Small } \\
\text { Large }\end{array}$ & $\begin{array}{l}k_{2}^{0}=k=k_{\mathrm{AC}}[\beta] \\
k_{0}^{2}=k=k_{\mathrm{AC}}[\beta ; F]\end{array}$ \\
\hline
\end{tabular}

Table 2. Classifications for the effects of intermolecular forces on the second nonradiative transition [Eq. (2)]. $k_{\text {ro }}$ and $k_{\text {no }}$ are the vibrational relaxation rates in the initial and final electronic states of the nonradiative transition, respectively. $\varrho_{\text {ac }}$ and $\varrho_{\text {ca }}$ are the densities of vibronically coupled states in the final and initial electronic states, respectively. Under different circumstances, changing the solvent is expected to change the vibrational relaxation rate $k_{\mathrm{no}}$, the nonradiative transition rate $k_{\mathrm{AC}}$, or the activation energy $E_{\mathrm{A}}$. The nonradiative transition rate may depend on the correlation time (not considered here) or the coupling probability where the latter may be factored into vibronic coupling energy $\beta$ and Franck-Condon $F$ factors. 


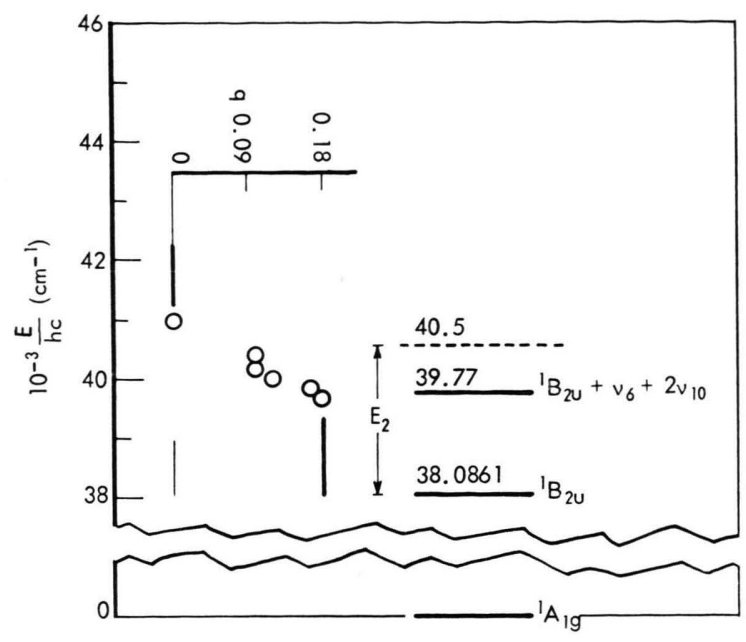

(a)

(b)

Fig. 1. Energy-level diagram for benzene. Left (a): The fluorescence yield $q$ of benzene vapor as a function of the excitation wavenumber (Ref. ${ }^{8},{ }^{9}$ ). Right (b) : Energy levels of benzene, including the zero-point vibrational level of the ${ }^{1} B_{2} u$ electronic state, and the final sublevel of the perturbed $6_{0}{ }^{1} 10_{0}{ }^{2}$ vibronic transition (Ref. ${ }^{19}$ ); and the average activation energy measured in solution, dashed at $E_{2} / h c=2400 \mathrm{~cm}^{-1}$ above the zero-point level (Ref. ${ }^{10,11}$ ). [If excitation in (a) is due to hot bands, the plotted energy of the circles should be raised slightly.]

\section{Mechanism}

We consider only an idealized stepwise mechanism (Fig. 2) in which either the vibrational relaxation of the primary product (Case I in Table 2) or the nonradiative transition itself (Case II) determines the rate $(k)$. This idealization of independent steps will break down in a more complete treatment, for the duration of the rate-determining interaction will depend at least partly on the average rate of the other fast process ${ }^{17}$.

In the gas state (Fig. $2 \mathrm{~A}$ ) the excitation (I) near $40,000 \mathrm{~cm}^{-1}$ (to $A_{r}$ ) populates excited vibrational sublevels of the ${ }^{1} \mathrm{~B}_{2 u}$ electronic state ${ }^{18-22}$. In vapors

17 W. Rhodes, B. R. Henry, and M. Kasha, Proc. Nat. Acad. Sci. (U.S.) 63, 31 [1969]. Some of the relevant correlation times are defined.

18 This may be seen by the analysis of the vibrational finestructure in the UV absorption spectrum of benzene ${ }^{19,20}$. One unexpected shift of $20 \mathrm{~cm}^{-1}$ occurs at a somewhat lower energy ${ }^{19}$, and the corresponding sublevel excited $\left(v_{6}+2 v_{10}\right)$ is indicated in Fig. 1. The relative ease of assigning the fine structure in the UV absorption to benzene vibrations indicates that physically the initial and final states of the nonradiative transition derive from characteristic but overlapping potential energy surfaces of their own, rather than from a common surface with a double minimum. However, the assignment should be re-examined with respect to considerations summarized by HERZBERG ${ }^{21}$.
A VAPOR ( 10 torr $)$

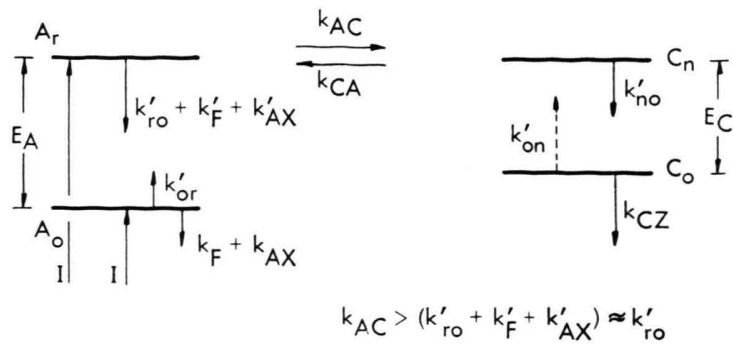

B LIQUID
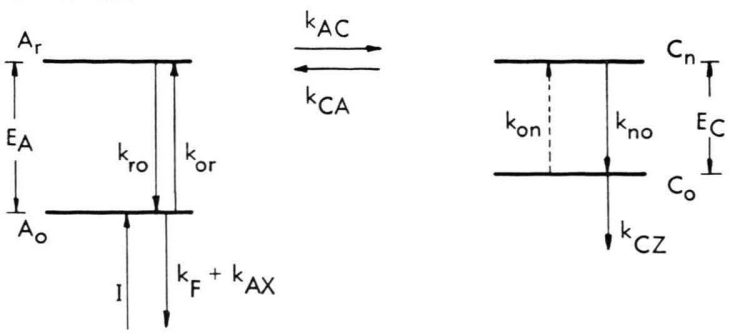

$$
\begin{gathered}
k_{A C}<k_{r O} \\
{\left[A_{r}\right]=\left[A_{0}\right] e^{-E_{A} / R T}}
\end{gathered}
$$

Fig. 2. Mechanism for an induced or partially induced nonradiative transition in benzene. Either the zero-point vibrational level $\left(A_{0}\right)$ or an excited level $\left(A_{r}\right)$ is populated by photon absorption (I photons/sec absorbed). A nonradiative transition from $\mathrm{A}_{\mathrm{r}}$ to $\mathrm{C}_{\mathrm{n}}$ occurs with a rate $k_{\mathrm{AC}}$ and produces a vibrationally excited product that may revert to $\mathrm{A}_{\mathrm{r}}$ (rate $k_{\mathrm{CA}}$ ). The excited vibrational levels $A_{r}$ and $C_{n}$ may relax (with rates $k_{r o}$ and $k_{\mathrm{n}}$ from $\mathrm{A}_{\mathrm{r}}$ and $\mathrm{C}_{\mathrm{n}}$ respectively) or be thermally populated (rates $k_{0 \mathrm{r}}$ and $\left.k_{0 \mathrm{n}}\right)$. Spontaneous emission $\left(k_{\mathrm{F}}\right)$ and nonradiative transitions $\left(k_{\mathrm{AX}}, k_{\mathrm{CZ}}\right)$ are indicated. Small differences of vibrational excitation are not distinguished, and primes (e. g., $k_{\text {or }}^{\prime}$ ) are used to show that different details occur in the different vibrational relaxation steps. Both the vibrational relaxation and the spontaneous emission occur with somewhat different rates from different sublevels. Intermolecular forces may affect the rates of vibrational relaxation (e.g., $\left.k_{\mathrm{no}}\right)$, the rates of the nonradiative transition step $\left(k_{\mathrm{AC}}\right)$, as well as the activation energy $E_{\mathrm{A}}$. Arguments given in the text are used to rule out the back reaction indicated by dashes.

of moderate pressure (up to 100 torr ${ }^{9}$ ) no subsequent fluorescence is found. The corresponding

19 J. H. Callomon, T. M. Dunn, and I. M. Mills, Phil. Trans. Roy. Soc., London 259, 499 [1966]. Notation and vibrational frequencies are listed.

20 F. M. Garforth and C. K. Ingold, J. Chem. Soc. 1948, 417.

21 G. Herzberg, Spectra of Diatomic Molecules, Van Nostrand, New York 1950, pp. 280 f., 315 f., 405 f., 445.

22 The threshold of the transition at $40,000 \mathrm{~cm}^{-1}$ may be due to (1) the increasing of the density of final states $\varrho_{\mathrm{ac}}$ with increasing energy ( $\Delta E$ large), (2) the occurrence of an electronic state not available at a lower energy $(\Delta E \sim 0)$, or (3) a crossing of potential energy surfaces (large change in geometry or force-constant, or small changes with $\Delta E$ large). ( $\Delta E$ is the electronic energy converted to vibrational energy.) 
nonradiative transition occurs with a rate $k_{\mathrm{AC}}$ where $k_{\mathrm{AC}}>\left(k_{\mathrm{ro}}^{\prime}+k_{\mathrm{F}}^{\prime}+k_{\mathrm{AX}}^{\prime}\right) \approx k_{\mathrm{ro}}^{\prime}$. (The definitions of the various rate constants are given in Fig. 2.) The vibrational relaxation rate $k_{\text {ro }}^{\prime}$ is pressure dependent and is slightly different for different vibrational sublevels. However, in all observed cases it is near the hard-sphere collision rate ${ }^{6,23}$. At 100 torr this gives a lower limit of $k_{\mathrm{AC}}>10^{8} \mathrm{sec}^{-1}$. An upper limit is obtained from the linewidth $\delta E / h c<1 \mathrm{~cm}^{-1}$ in the fine structure of the UV absorption of benzene. Using the uncertainty relation, $k_{\mathrm{AC}}<\delta E / h \approx 10^{11} \mathrm{sec}^{-1}$.

In liquid solutions (Fig. 2 B) the fluorescence quantum yield $q$ is independent of the frequency of the exciting light ${ }^{25,26}$ so that $k_{\mathrm{AC}}<k_{\mathrm{r} o}$, and $\left[\mathrm{A}_{\mathrm{r}}\right]=\left[\mathrm{A}_{0}\right] e^{-E_{\mathrm{A}} / k T}$, where the brackets indicate concentrations and $E_{\mathrm{A}}$ is the thermal activation energy.

Rate-Determining Step. The activation energy in solution $E_{2} / h c=2400 \mathrm{~cm}^{-1}$ agrees with the threshold energy in the gas state (Fig. 1) so little thermally-excited back reaction $\left(k_{\text {on }}\right)$ occurs in liquids. Otherwise the activation energy would have been the difference $E_{2}=\left(E_{\mathrm{A}}-E_{\mathrm{C}}\right){ }^{27}$. The measured $E_{2}$ becomes $E_{\mathrm{A}}$ of the mechanism, and the pre-exponential $k_{2}{ }^{0}$ becomes the rate $k$ of the rate-determining step.

The Arrhenius pre-exponential measured in liquids $k_{2}{ }^{0}$ must be equal to or less than the nonradiative transition rate $k_{\mathrm{AC}}, k_{2}{ }^{0} \leqq k_{\mathrm{AC}}$, and also $k_{\mathrm{AC}}<k_{r_{0}}$. Various measurements on other systems would place $k_{\mathrm{r} 0} \approx 10^{11} \mathrm{sec}^{-1}$ (see Refs. ${ }^{28-32}$ ), but the resulting inequality $k_{2}{ }^{0}<k_{\mathrm{r} 0} \approx 10^{11} \mathrm{sec}^{-1}$ is not

${ }^{23}$ In a vapor of moderate pressure, it is also known that $\left(k_{\mathrm{F}}+k_{\mathrm{AX}}\right)>k_{\text {or }}^{\prime}$, because no thermal quenching of fluorescence or of triplet state formation is found (up to 700 torr of propane gas) ${ }^{24}$, when low-energy excitation (to a partially equilibrated $\left.A_{0}\right)$ is used. Using $\left(k_{\mathrm{F}}+k_{\mathrm{AX}}\right)=1.4$ $\times 10^{7} \mathrm{sec}^{-1}\left(\mathrm{see}^{5,12}\right)$ shows that the upward vibrational excitation of about $2000 \mathrm{~cm}^{-1}\left(k_{\text {or }}^{\prime}\right)$ requires more than $10^{2}$ hard-sphere collisions.

24 E. K. C. Lee, H. O. Denschlag, and G. A. Haninger, J. Chem. Phys. 48, 4547 [1968].

25 C. L. Braun, S. Kato, and S. Lipsky, J. Chem. Phys. 39, 1645 [1963].

26 J. B. Birks, J. C. Conte, and G. Walker, J. Phys. (Proc. Phys. Soc.) B 1, 934 [1968].

27 The location of state $C_{0}$ in Fig. 2 is immaterial as long as it is not close to state $A_{r}$, and even then the Boltzmann population factor is near unity and the backward step can be neglected.

28 The rate for vibrational relaxation in the ${ }^{1} B_{2 u}$ state of benzene dissolved in liquids is not known. However in the ground state of benzene it is reported to be about $10^{10} \mathrm{sec}^{-1}$ $\left(\right.$ see $^{29-31}$ ). In an excited state of azulene it is reported to be about $10^{11} \sec ^{-1}\left(\operatorname{see}^{32}\right)$. consistent with the activation energy $E_{2} / h c=2400$ $\mathrm{cm}^{-1}$ and the degree of fluorescence quenching, which gives $k_{2}{ }^{0}>10^{11} \mathrm{sec}^{-1}$ (see Ref. ${ }^{10}$ ). We must either abandon the simple Arrhenius approximation and use a more exact representation of the rate ${ }^{33}$, or use a higher rate for vibrational relaxation ${ }^{34}$, $k_{\mathrm{r} 0} \approx 5 \times 10^{12} \mathrm{sec}^{-1}$. In the first case, the levels drawn in Fig. 2 must represent a manifold of vibrational sublevels extending upward from a threshold wavenumber of about $1600 \mathrm{~cm}^{-1}$ and leading to an average ${ }^{35} E_{2} / h c=2400 \mathrm{~cm}^{-1}$.

The rate-values $\left(k_{2}{ }^{0}=k\right)$ obtained both in the vapor and in the liquid are similar to the rates expected for vibrational relaxation in the product. If this is the rate-determining step (Case I, Table 2), $k_{2}{ }^{0}=k=k_{\text {no }}$, and in the macroscopic vapor under steady-state illumination

$$
\left[\mathrm{C}_{\mathrm{n}}\right] /\left[\mathrm{A}_{\mathrm{r}}\right]=k_{\mathrm{AC}} / k_{\mathrm{CA}}=\varrho_{\mathrm{ac}} / \varrho_{\mathrm{ca}} .
$$

$\varrho_{\mathrm{ac}}$ and $\varrho_{\mathrm{ca}}$ are the densities of coupled states for the forward and reverse nonradiative transitions, respectively. Also, in liquids

$$
\left[\mathrm{C}_{\mathrm{n}}\right]=\left[\mathrm{A}_{\mathrm{o}}\right]\left(\varrho_{\mathrm{ac}} / \varrho_{\mathrm{ca}}\right) \exp \left\{-E_{\mathrm{A}} / k T\right\} .
$$

Although vibrational relaxation of the product has been invoked as a rate-determining step in photochemical tautomerizations ${ }^{36,37}$, in the present case there is a quantitative difficulty. When $2537 \mathrm{~A}$ excitation is used, the vibrational relaxation of the populated benzene levels requires few hard-sphere collisions ${ }^{6}$. If we apply this result to both the initial $\left(\mathrm{A}_{\mathrm{r}}\right)$ and final $\left(\mathrm{C}_{\mathrm{n}}\right)$ resonant levels under consideration $\left(k_{\mathrm{no}}^{\prime} \approx k_{\mathrm{ro}}^{\prime}\right.$, about $450 \mathrm{~cm}^{-1}$ higher than reached

29 G. G. Sukhotina and M. I. Shakhparonov, Russ. J. Phys. Chem. 39, 1192 [1965].

30 J. L. Hunter, E. F. Carone, H. D. Dardy, and J. A. BuCARO, J. Acoust. Soc. Amer. 40, 313 [1966].

31 C. I. O'Connor and J. P. Schlupf, J. Acoust. Soc. Amer. 40, 663 [1966].

32 P. M. Rentzepis, Chem. Phys. Letters 2, 117 [1968].

33 S. H. Lin, J. Chem. Phys. 44, 3759 [1966].

34 The observed linewidth in the vibrational fine-structure of the UV absorption, about $50 \mathrm{~cm}^{-1}$ in liquid hydrocarbons after elimination of hot bands, gives an upper limit for the ${ }^{1} \mathrm{~B}_{2 \mathrm{u}}$ state, $k_{\mathrm{ro}} \leqq 10^{13} \mathrm{sec}^{-1}$.

35 In such a case, the pre-exponential measured in liquids $k_{2}{ }^{0}$, being an average of rates for several energy levels, cannot be compared directly to rate constants obtained in the gas state for individual vibrational sublevels.

36 L. Kaplan and K. E. Wilzbach, J. Amer. Chem. Soc. 90, 3291 [1968].

37 I. Haller, J. Chem. Phys. 47, 1117 [1967]. 
with 2537 A excitation), there is little room to explain the irreversibility of the transition in the gas state, which requires $k_{\mathrm{no}}^{\prime}>k_{\mathrm{ro}}^{\prime}$. One may expect the irreversibility to appear more naturally when the rate-determining step is the nonradiative transition itself, $k_{2}{ }^{0}=k=k_{\mathrm{AC}}$ (Table 2, Case II). A forward bias in the densities of states $\varrho_{\mathrm{ac}}>\varrho_{\mathrm{ca}}$ then drives the reaction.

\section{Solvent Effect}

In the liquid solutions studied the distance between the molecules does not change much when the solvent is changed, so the intermolecular force is approximately proportional to the minimum depth of the bimolecular potential. As a convenient mea-

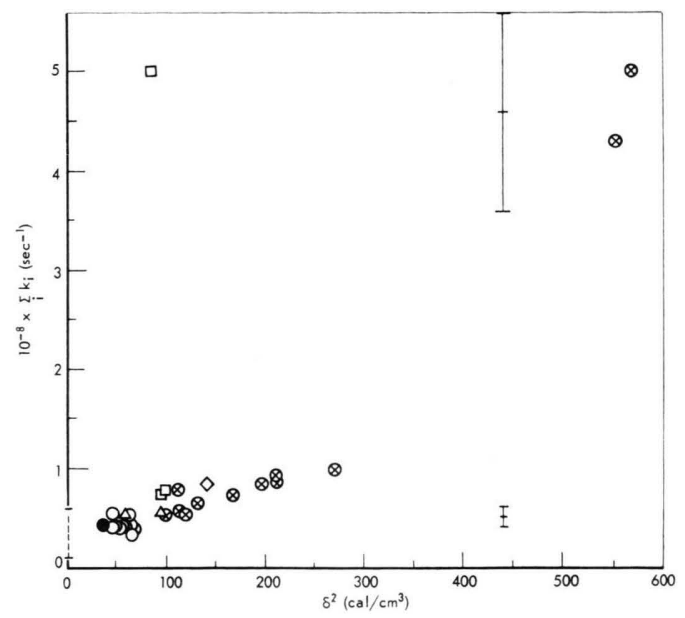

Fig. 3. Dependence of the nonradiative transition rate on the solvent. The rate of all nonradiative transitions [Eq. (1)] as a function of the cohesive energy density $\delta^{2}$ of the solvent. Points are keyed to Table 1. Bars give the estimated maximum experimental error possible at limiting positions on the vertical axis. The dashed portion of the vertical axis gives the nonradiative transition rate for a hypothetical benzene vapor (to illustrate the relevant variables only) having a zero-point vibrational level and one thermally equilibrated active level $1600 \mathrm{~cm}^{-1}$ higher (Table 1, footnote $\mathrm{d}$ ).

38 J. H. Hildebrand and R. L. ScotT, Regular Solutions, Prentice-Hall, Englewood Cliffs, New Jersey 1962.

39 M. Koyanagi, J. Mol. Spectry. 25, 273 [1968].

40 The UV absorption of benzene in carbon tetrachloride and other properties of these solutions indicate that complexes are formed ${ }^{41}$. About $8 \%$ of the benzene molecules in a carbon tetrachloride solvent are predicted to be present as complexes. In chloroform, the UV absorption also suggests that complexes are present between the solvent and benzene in the ground state ${ }^{12}$. However, a concentration of $8 \%$ is not great enough to explain the fluorescence quenching of benzene in chloroform. From the cohesive energy density (Fig. 3 ), we predict a quantum yield of $q=0.04$ for free molecu- sure of this depth we take the cohesive energy density $\delta^{2}$ of the solvent ${ }^{38}$. It correlates increasing nonradiative decay rates with increasing intermolecular force, Fig. 3. (A straight line is predicted if the coupling energy of the rate-determining step is proportional to the intermolecular force.)

It is seen that the nonradiative transitions are exceptionally rapid in water and chloroform. Much of this acceleration is caused by energetic electrostatic- and London-interactions, as shown by the correlation between the nonradiative transition rate and the $(0-0){ }^{1} B_{2 u}-{ }^{1} A_{1 g}$ UV absorption intensity, which increases with increasing electrostatic- and London-interactions ${ }^{39}$ and for the solvents considered is most intense in water and chloroform ${ }^{12}$. The high rate in water is to be expected from the high dipole moment. In chloroform, however, the rate is far above that expected. In this solvent, the integrated UV absorption suggests that complexes with benzene are present ${ }^{12}$. In such complexes the effects of electrostatic- and London-interactions may be greater than they are in randomly oriented spheres of solvation ${ }^{40-42}$.

\section{Intramoleculer Coupling}

Symmetry Rules. If the rate-determining step is a nonradiative electronic transition coupled through intramolecular vibrations (Case II B, Table 2), the intermolecular forces may induce or accelerate the transition by removing restrictions of symmetry. For example, the primary product may be the ${ }^{1} \mathrm{~A}_{1 \mathrm{~g}}$ ground state. (A relatively large density of final states $\varrho_{\mathrm{ac}}$ favors such an internal conversion at 40,000 $\mathrm{cm}^{-1}$ ( see ${ }^{15,43}$ ). In this case, the geometry change that accompanies the nonradiative transition is small, and the corresponding vibronic selection rules ${ }^{33,44}$ show that the transition is coupled by the $b_{2 u}\left(v_{14}\right.$ or $v_{15}$ ) vibrations in the isolated molecule ${ }^{19}$. In the presence of neighboring molecules the electronic

les of benzene in chloroform at $25^{\circ} \mathrm{C}$. Considerably more than $8 \%$ of the benzene molecules must be present as complexes in the excited state to account for the difference between this predicted yield and the observed $q=0.005$. Additional complexes are formed in the excited state ${ }^{42}$.

41 R. Anderson and J. M. Prausnitz, J. Chem. Phys. 39, 1225 [1963].

42 P. K. Ludwig and C. D. Amata, J. Phys. Chem. 72, 3725 [1968].

43 M. Bixon and J. Jortner, J. Chem. Phys. 48, 715 [1968].

44 A. C. Albrecht, J. Chem. Phys. 38, 354 [1963] ; 33, 156, 169 [1960]. 
wave functions of benzene are perturbed so that the forbidden $(0-0){ }^{1} B_{2 u}-{ }^{1} A_{1 g}$ UV absorption appears. At the same time, nonradiative transitions coupled by $e_{1 \mathrm{u}}$ and $e_{2 g}$ vibrations (for example) are introduced. (We have been led to look in particular for transitions coupled by the $v_{6} e_{2 g}$ and $\nu_{10} e_{1 g}$ vibrations because their UV-excitation near 40,000 $\mathrm{cm}^{-1}$ (Fig. 1) is perturbed ${ }^{19}$.)

Benzvalene (Fig. 4) is a photochemical product obtained from benzene ${ }^{36,45}$ (see "Discussion" below) and the corresponding vibronic rules are given in
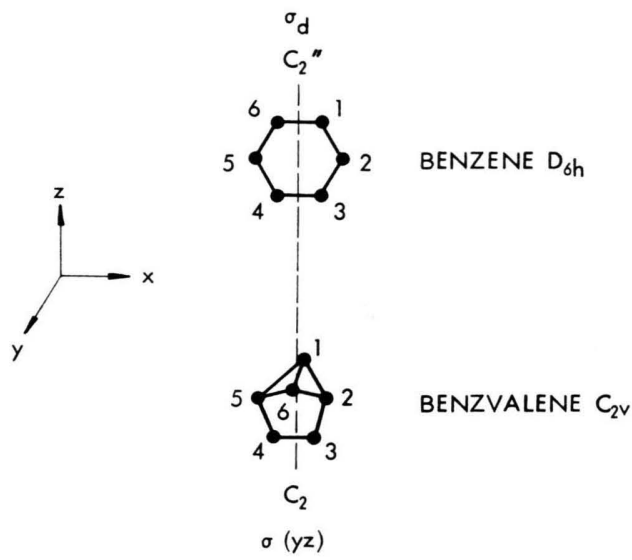

Fig. 4. Equilibrium nuclear configurations for the tautomerization of benzene to benzvalene.

Table 3. If the ${ }^{1} \mathrm{~A}_{1}$ ground state of benzvalene is the primary product there are eleven vibrations of four symmetries (including the $e_{2 g}$ ) that couple the transition in the isolated molecule. Intermolecular forces may induce coupling by some of the remaining vibrations. Also, another symmetry restriction may apply. This is the WOODWARD-HOFFMANN correlation ${ }^{46}$, which is invoked in tautomerizations for which the geometry change is relatively large. The correlation does not favor the ${ }^{1} B_{2 u}-{ }^{1} A_{1}$ transition, but does favor that of ${ }^{1} \mathrm{~B}_{1 \mathrm{u}}$-benzene to ${ }^{1} \mathrm{~B}_{1}$-benzvalene ${ }^{37}$. Again the intermolecular forces may induce the transition by introducing some ${ }^{1} \mathrm{~B}_{1 \mathrm{u}}$ and ${ }^{1} \mathrm{~B}_{1}$ symmetry into the initial and final states, respectively.

45 I. E. DenBesten, L. Kaplan, and K. E.Wilzbach, J. Amer. Chem. Soc. 90, 5868 [1968].

46 R. Hoffmann and R. B. Woodward, Accounts Chem. Res. 1,17 [1968].

47 J. Petruska, J. Chem. Phys. 34, 1120 [1961].

48 I. B. Berlman, Handbook of Fluorescence Spectra of Aromatic Molecules, Academic Press, New York 1965.

\begin{tabular}{|c|c|c|c|c|c|c|}
\hline & \multicolumn{4}{|c|}{ BENZVALENE } \\
\hline & & & \multicolumn{2}{|c|}{$\sigma_{X z}-$ SYMMETRIC } & \multicolumn{2}{|c|}{$\sigma_{X z}-$ ANTISYMMETRIC } \\
\hline & & & $A_{1}$ & $\mathrm{~B}_{1}$ & $\mathrm{~A}_{2}$ & $\mathrm{~B}_{2}$ \\
\hline \multirow{4}{*}{$\begin{array}{l}\text { U } \\
\underset{\mathrm{N}}{N} \\
\underset{\mathrm{D}}{\mathrm{D}}\end{array}$} & \multirow{2}{*}{ 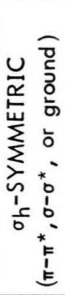 } & 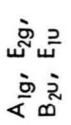 & $\begin{array}{l}a_{1 g} \\
e_{2 g} \\
b_{2 u} \\
e_{1 u}\end{array}$ & $\begin{array}{l}a_{2 g} \\
e_{2 g} \\
b_{1 u} \\
e_{1 u}\end{array}$ & $\begin{array}{l}b_{2 g} \\
e_{1 g} \\
\cdot e_{2 y}\end{array}$ & $\begin{array}{r}e_{1 g} \\
a_{2 u} \\
\cdot e_{2 u}\end{array}$ \\
\hline & & 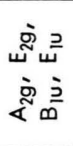 & $\begin{array}{l}a_{2 g} \\
e_{2 g} \\
b_{1 u} \\
e_{1 u}\end{array}$ & $\begin{array}{l}a_{1 g} \\
e_{2 g} \\
b_{2 u} \\
e_{1 u}\end{array}$ & $\begin{array}{r}\mathbf{e}_{1 \mathrm{~g}} \\
\mathbf{a}_{2 \mathrm{U}} \\
\cdot \mathbf{e}_{2 \mathrm{2u}}\end{array}$ & $\begin{array}{l}b_{2 g} \\
e_{1 g} \\
\cdot e_{2 u}\end{array}$ \\
\hline & \multirow{2}{*}{ 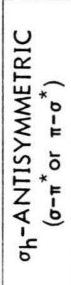 } & 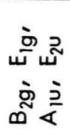 & $\begin{array}{r}b_{2 g} \\
e_{1 g} \\
\cdot e_{2 U}\end{array}$ & $\begin{array}{r}\mathbf{e}_{1 \mathrm{~g}} \\
\mathrm{a}_{2 \mathrm{U}} \\
\cdot \mathbf{e}_{2 \mathrm{u}}\end{array}$ & $\begin{array}{l}a_{1 g} \\
e_{2 g} \\
b_{2 u} \\
e_{1 u}\end{array}$ & $\begin{array}{l}a_{2 g} \\
e_{2 g} \\
b_{1 u} \\
e_{1 u}\end{array}$ \\
\hline & & 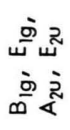 & $\begin{array}{r}\mathbf{e}_{1 \mathrm{~g}} \\
\mathrm{a}_{2 \mathrm{u}} \\
\cdot \mathbf{e}_{2 \mathrm{u}}\end{array}$ & $\begin{array}{l}b_{2 g} \\
e_{1 g} \\
\cdot e_{2 v}\end{array}$ & $\begin{array}{l}a_{2 g} \\
e_{2 g} \\
b_{1 u} \\
e_{1 u}\end{array}$ & $\begin{array}{l}a_{1 g} \\
e_{2 g} \\
b_{2 u} \\
e_{1 U}\end{array}$ \\
\hline
\end{tabular}

Table 3. Intramolecular vibronic coupling of benzene with benzvalene. The small letters in the table give the vibrational normal modes of benzene that can couple the electronic states of benzene (capital letters in left margin) with those of benzvalene (capital letters in top margin). Out-of-plane vibrations of comparatively low frequency are surrounded by bold squares, and a dot precedes the symmetry of the high-amplitude $v_{16}$ vibration $\left(v_{16}=237.3 \mathrm{~cm}^{-1}\right)$.

Substitution Effects. Perturbations that are caused by intramolecular substitution exceed the intermolecular ones, even when the former are as weak as those produced by alkyl-substitution. For example, alkyl substitutions cause the $(0-0)$ absorption peak in the ${ }^{1} \mathrm{~B}_{2 \mathrm{u}}-{ }^{1} \mathrm{~A}_{1 \mathrm{~g}} \mathrm{UV}$ absorption spectrum to appear ${ }^{47}$, and in so doing they are considerably more effective than intermolecular forces ${ }^{39}$. Also as expected the alkyl substitutions cause an increase in the spontaneous emission rate, and this is shown in Fig. $5^{48}$. However, the total nonradiative decay rate $\left(\cong k_{1}+k_{2}\right)$ is not increased by the substitution ${ }^{49-51}$. Clearly the solvent perturbation that leads to increasing nonradiative transition rates is different from the in-plane perturbations that lead to inhanced $(0-0)$ UV absorption and inhanced spontaneous emission.

49 That nonradiative transitions of alkyl-benzenes and benzene itself may be usefully compared is indicated by the close resemblance in the gas state of the nonradiative transitions of toluene and benzene ${ }^{\mathbf{5 0}, \mathbf{5 1}}$.

50 C. S. Burton and W. A. Noyes, Jr., J. Chem. Phys. 49, 1705 [1968].

51 G. M. Breuer and E. K. C. Lee, J. Chem. Phys. 51, 3130 [1969]. 


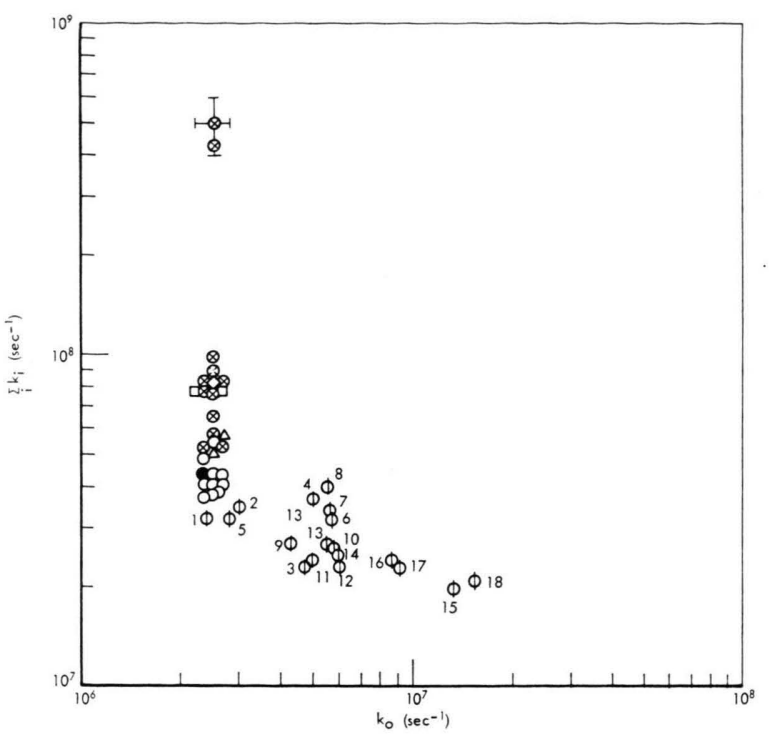

Fig. 5. Correlation of radiative and nonradiative transition rates. The total rate at $25^{\circ} \mathrm{C}$ of all nonradiative transitions for benzene dissolved in 28 liquids (symbols keyed to Table 1) and for 18 alkyl-substituted benzene compounds (numbered points) in cyclohexane measured by BERLMAN ${ }^{48}$, as a function of the spontaneous emission rate $k_{0}$. Numbered points are 1) benzene, 2) perdeuterobenzene, 3) mesitylene, 4) 1,3,5-triethylbenzene, 5) benzylalcohol, 6) phenylcyclohexane, 7) secbutylbenzene, 8) isopropylbenzene, 9) propylbenzene, 10) ethylbenzene, 11) toluene, 12) perdeuterotoluene, 13) m-xylene, 14) o-xylene, 15) p-xylene, 16) perdeutero-p-xylene, 17) p-ethyltoluene, 18) 1,2,4-trimethylbenzene. (The bars give the estimated absolute error for the least reliable point in the series of solvents.)

The intermolecular forces might mix in planarantisymmetric states not available from alkyl-substitution. For example, out-of-plane vibrational modes may couple the ${ }^{1} \mathrm{~B}_{2 u^{-}}$and ${ }^{1} \mathrm{~A}_{1 \mathrm{~g}}$-benzene states in the presence of intermolecular forces ${ }^{52-54}$. However, this mechanism cannot account for the solvent effect if benzvalene is the primary product. Consider the data for mesitylene. In the mesitylene tautomer both the $\sigma_{x y}$ and $\sigma_{x z}$-symmetric symmetries of benzvalene are removed to some degree by the alkyl groups. However, the nonradiative transition rate (Fig. 5) is affected less by the substitution than it is by a polar solvent. That the $\sigma_{x z}$-symmetry is not crucial to induced tautomerization is also indicated by the isolation of both 1,2,4-tri-t-butyl- and 1,3,6-tri-t-butyl-

52 This mechanism can be checked by calculation of the sort carried out by ALBRECHT on vibronic absorption ${ }^{44}$ and by Young on nonradiative transitions ${ }^{53}$. The matrix elements are known in general ${ }^{16}, 33,53$, trial wave functions are available, and accurate methods to include solvent perturbations have been developed ${ }^{54}$. benzvalenes ${ }^{45}$. The latter, but not the former, is symmetric about the $\sigma_{x z}$ plane.

We are led to believe that (1) if the primary product of the nonradiative transition is a valence tautomer such as benzvalene, the solvent-induced nonradiative transitions are probably not caused by a breakdown of symmetry, and (2) if the intermolecular forces do break down a crucial symmetry (related to the vibronic rules), the primary product is probably planar (for example, ${ }^{1} \mathrm{~A}_{1 \mathrm{~g}}$-benzene), and the solvent perturbs this symmetry.

\section{Discussion}

Solvent Effects. In the nonradiative transition step, the particular initial and final states that interact at a given energy will depend on the solvent if the energy of one state shifts with respect to the other when the solvent is changed. However, in liquid solutions there is a large inhomogeneous broadening of the energy levels ${ }^{55}$. The broadening is not much different from the frequency shifts that can be induced in the electronic energy of a nonpolar molecule by changing the solvent ${ }^{55}$. As the shift does not greatly exceed the width, we do not expect the coupled initial and final states to change much when the solvent is changed. In particular, if the nonradiative transition is a ${ }^{1} \mathrm{~B}_{2 \mathrm{u}}-{ }^{1} \mathrm{~A}_{1 \mathrm{~g}}$ internal conversion, the effect of solvent on the nonradiative transition does not derive from the relative shift of the electronic energies of the coupled states. The solventinduced shift of the ${ }^{1} \mathrm{~B}_{2 u}-{ }^{1} \mathrm{~A}_{1 \mathrm{~g}}$ electronic absorption frequency has been measured, and it does not correlate with the rate of the nonradiative transition as a function of solvent ${ }^{12}$.

If the vibrational relaxation of the primary product is the rate-determining step (Case I), the coupling energy and the observed transition rate should increase with increasing intermolecular force and should be comparatively insensitive to molecular symmetry ${ }^{56}$, in accord with the experimental data. Similarly the data are in accord with a mechanism in which the rate-determining step is a nonradiative electronic transition (Case II) coupled through the

53 J. H. Young, J. Chem. Phys. 51, 4061 [1969].

54 W. Liptay, H. J. Schlosser, B. Dumbacher, and S. HüNIG, Z. Naturforsch. 21 a, 1613 [1968].

55 O. V. Sverdlova, Opt. Spectry. 6, 223 [1959].

56 R. Zwanzig, J. Chem. Phys. 34, 1931 [1961]. 
intermolecular coordinate (II A) ${ }^{57-59}$. (In this latter case the competition between the nonradiative transition and the vibrational relaxation must be considered in detail as a function of the distance between the molecules.)

If a rate-determining nonradiative electronic transition arises from the vibronic coupling of intramolecular vibrations (II B), there are a number of additional mechanisms possible. Increasing rates will result from increased coupling probability that is related in turn either to increasing vibronic coupling energy $[\beta$ in Table 2] or increasing Franck-Condon overlap $(F)^{33,64,65}$. The coupling energy $\beta$ will increase when symmetry restrictions are removed (treated above) or when a change in the shape of the electronic wave functions occurs without reduction of symmetry ${ }^{44}$. A sensitivity of the Franck-Condon overlap $F$ to intermolecular forces (Table 2) is expected only when the potential energy surfaces of the initial and final states are nested and when $\Delta E$, the amount of electronic energy converted to vibrational energy, is large. $\Delta E$ should be large because the vibrational wave functions are most sensitive to intermolecular forces at high amplitudes of vibration ${ }^{16,66}$. If the potential energy surfaces are not nested, $E_{2}=E_{\mathrm{A}}$ is lowered when the vibrational anharmonicities added by intermolecular forces lower the energy of the intersection ( $F$ remaining about the same).

Benzvalene as Product. In the gas state with increasing wavenumber of excitation, increasing amounts of ${ }^{1} \mathrm{~B}_{2 \mathrm{u}}$-benzene disappear (Fig. 1 a) ${ }^{8,9}$ and increasing amounts of benzvalene are isolated ${ }^{36}$.

57 R. B. Gerber, Proc. Roy. Soc. London A 309, 221 [1969].

58 A. B. Callear, in: Photochemistry and Reaction Kinetics, P. G. Ashmore, F. S. Dainton, and T. M. Sugden, Ed., University Press, Oxford 1967, p. 175.

59 It is assumed that fundamental vibrational frequencies in the isolated benzene molecule (the lowest being $v_{16}=237.3$ $\mathrm{cm}^{-1}$ ) are higher than intermolecular frequencies, so the two types of vibration are physically distinguishable. When intermolecular forces are highly energetic, as with F-centers in solids ${ }^{60}$, with polar molecules dissolved in polar liquids ${ }^{61,62}$, and with hydrogen-bounded molecules in alcohols ${ }^{63}$, nonradiative transitions may be produced by displacements of the intermolecular coordinate. However, the nonpolar benzene molecule is bound less energetically to neighboring molecules.

60 K. Huang and A. Rhys, Proc. Roy. Soc. London 204, 406 [1950].

61 E. Lippert, W. Lüder, and H. Boos, Advan. Mol. Spectry. 1, 443 [1962].

62 J. W. Eastman, Spectrochim. Acta, in press [1970].

63 J. W. Eastman, Ber. Bunsenges. Physik. Chem. 73, 407 [1969].
Also, the amount of benzene that disappears and the amount of benzvalene isolated from the vapor both increase when added gases are introduced ${ }^{67,68}$. In liquid solutions, both the disappearance of the ${ }^{1} B_{2 u}$ state of benzene ${ }^{25}$ and the isolation of benzvalene ${ }^{36}$ are independent of the excitation wavenumber. In addition, neither the observed nonradiative transition rate (Fig. 5 and Ref. ${ }^{50}$ ) nor the isolation of benzvalene ${ }^{45}$ are markedly sensitive to alkyl-group substitution. These correlations suggest that benzvalene is a product of the induced or partially-induced transition discussed (rate $k_{2}$ ) ${ }^{69}$. The primary product of the nonradiative transition may be the ${ }^{1} \mathrm{~A}_{1}$ ground state of benzvalene, the ${ }^{1} \mathrm{~A}_{1 \mathrm{~g}}$ ground state of benzene that subsequently converts to the tautomer ${ }^{70}$, or other intermediates ${ }^{69}$.

\section{Conclusions}

Rate-determining Step. In an idealized step-wise mechanism (Fig. 2), the rate-determining step may be the vibrational relaxation of the primary product (Table 2, Case I, induced by intermolecular forces and bearing no particular relation to the intramolecular symmetry of benzene), or the nonradiative transition [Case II, caused by displacements in the intermolecular coordinate with symmetry again irrelevant (II A), or by intramolecular vibrational displacements related to molecular symmetry (II B) ]. In the vapor $10^{8}<k_{\mathrm{AC}}<10^{11} \mathrm{sec}^{-1}$ at 100 torr, and $k_{\mathrm{AC}}>k_{\mathrm{ro}}^{\prime}$. If vibrational relaxation of the product is rate-determining, $k_{\mathrm{CA}}>k_{\mathrm{no}}^{\prime}$, and $k_{\mathrm{no}}^{\prime}>k_{\mathrm{ro}}^{\prime}$. However, vibrational relaxation of the initial resonant

64 J. P. Byrne, E. F. McCoy, and I. G. Ross, Aust. J. Chem. 18, 1589 [1965].

65 W. Siebrand, J. Chem. Phys. 49, 1860 [1968].

66 O. Schnepp and K. Dressler, J. Chem. Phys. 42, 2482 [1965].

67 The fluorescence of benzene is quenched by 1,3-pentadiene (see ${ }^{68}$ ), and the isolation of benzvalene is catalyzed by cis-2-butene ${ }^{36}$. However, different mechanisms have been invoked for the two effects, and under some conditions it is known that butene quenches fluorescence insignificantly $\left(\right.$ see $\left.^{9,24}\right)$.

68 L. M. Stephenson, D. G. Whitten, and G. S. Hammond, in: Chemistry of Ionization and Excitation, G. R. A. JoHNson, ed., Taylor and Francis, London 1967.

69 D. Phillips, J. Lemaire, C. S. Burton, and W. A. Noyes, JR., Adv. in Photochem. 5, 329 [1968].

70 For a favorable Franck-Condon overlap to be achieved in the tautomerization we may expect many excitations in the $v_{16}$ mode of benzene, which has a high amplitude in the direction of the tautomerization. 
sublevel $\left(A_{r}\right)$ and the final level $\left(C_{n}\right)$ may both require only a few collisions, so $k_{\mathrm{no}}^{\prime} \sim k_{\mathrm{ro}}^{\prime}$. In such a case, the nonradiative transition $\left(k_{\mathrm{AC}}\right)$ must be the rate-determining step. Such an irreversible nonradiative transition requires both that $k_{\mathrm{AC}} / k_{\mathrm{ro}}^{\prime}>1$ and $k_{\mathrm{CA}} / k_{\mathrm{no}}^{\prime}<1$, so $k_{\mathrm{AC}} \gg k_{\mathrm{CA}}$. This can be caused by a forward bias in the density of states $\varrho_{\mathrm{ac}}>\varrho_{\mathrm{ca}}$.

In liquids $k_{\mathrm{AC}}<k_{\mathrm{ro}}$ and the measurements on fluorescence quenching give $k_{2}{ }^{0}=k \sim 10^{11}-10^{13} \mathrm{sec}^{-1}$ when a single activation energy $E_{2} / h c=2400 \mathrm{~cm}^{-1}$ is adopted. These data are not consistent with values of $k_{\mathrm{r} 0}$ that have been measured for the ground state of benzene and for an excited state in azulene, $k_{\mathrm{r} 0} \sim 10^{10}-10^{11} \mathrm{sec}^{-1}$. Either the vibrational relaxation of the levels coupled by the nonradiative transition in benzene is considerably more rapid, $k_{\mathrm{r} 0} \sim 10^{12} \mathrm{sec}^{-1}$ in liquids, or the activation energy should be spread over several levels starting above a threshold of about $1600 \mathrm{~cm}^{-1}$.

Solvent Effects. Concerning the effects of intermolecular forces, the conclusions may be summarized as follows. First, when the rate-determining step is the vibrational relaxation of the primary product (Case I) or a nonradiative transition coupled by intermolecular motion (II A), the increasing rate with increasing intermolecular force is expected, for the intermolecular coordinate enters explicitly in the transition probability. In either of these cases the induced nonradiative decay becomes slower than spontaneous emission at very low pressures in the gas phase. If nonradiative transitions persist at low pressure, the induced decay may arise from an acceleration of nonradiative transitions already coupled by intramolecular vibrations in the isolated molecule (II B). This may be caused by reductions of molecular symmetry, with respect to which the following conclusions may be drawn:

1) If the primary product is benzvalene, and if either the Woodward-Hoffmann or vibronic symmetry rules are valid, the intermolecular forces do not act to break the symmetry restrictions. This is because the rate is not significantly accelerated by alkyl-substitutions, and these perturb the relevant symmetry more than the intermolecular forces.

71 Measurement of the activation energy may be possible in solvents such as glycerol or water that are rigid enough to trap the benzvalene before it reconverts to benzene. The amount of trapped benzvalene may be determined after conversion to more stable derivatives.
2) When the primary product is planar (for example, benzene ${ }^{1} A_{1 g}$ ) the intermolecular forces may mix in planar-antisymmetric states and introduce coupling by out-of-plane vibrations.

Also the effects of intermolecular forces (under II) may not be due to a breakdown of symmetry but to variations in:

i) $\Delta E$, the electronic energy converted to vibrational energy during the transition. However in liquids the inhomogeneous broadening of the vibronic levels is so large that this seems unlikely. If the primary product is ${ }^{1} \mathrm{~A}_{1 \mathrm{~g}}$-benzene, the variation in $\Delta E$ does not explain the solvent effect observed, for there is no correlation between the nonradiative transition rate and the changes in $\Delta E$, which have been measured;

ii) Franck-Condon overlap, $F$. A solvent is expected to significantly affect $F$ only when $\Delta E$ is large and the potential energy curves are nested at the transition energy (possible when the product is the ground electronic state of benzene and the threshold energy derives from the increasing density of states with increasing energy);

iii) The energy at which two potential energy surfaces intersect, as expected when $\Delta E$ and the geometry change (or force constant change) are both large (for example, when ${ }^{1} \mathrm{~A}_{1}$-benzvalene is the primary product).

The mechanisms ii) and iii) depend on anharmonicities in the potential energy surfaces and their sensitivity to intermolecular forces.

Benzvalene. Correlations between the nonradiative transition (rate $k_{2}$ ) and the formation of benzvalene suggest that the tautomer is a product of the transition. If so, the activation energy for its formation in liquids should be $2400 \mathrm{~cm}^{-1}$ (see ${ }^{71,72}$ ), and the formation may be catalyzed by carbon tetrachloride, chloroform, possibly 1,3-pentadiene, or other complex-forming compounds, as well as by molecules of high dipole moment and polarizability (Fig. 3). The geometry change that occurs in the tautomerization is relatively large, so the FranckCondon overlap may require many vibrational excitations in the primary product of the initial nonradiative transition step. This product may be the

72 This may also be the activation energy for the disappearance of triplet states of benzene in liquids. 
ground state of benzvalene or the ground state of benzene that leads in turn to the tautomer. In the latter case, if the rate-determining step is the ${ }^{1} \mathrm{~B}_{2 u}-$ ${ }^{1} \mathrm{~A}_{\mathrm{Ig}}$ internal conversion coupled by intramolecular vibrations, the formation of benzvalene might be catalyzed by chemical substitutions that reduce the planar-symmetric symmetry ${ }^{73}$.

${ }^{73}$ Nonradiative transitions are exceptionally rapid in benzyl-
Acknowledgments

The work reported here was financed by a fellowship from the Alexander von Humboldt Stiftung. The author wishes to thank Professor WolfGang LiPTAY for his hospitality and stimulating arguments. The author is also indebted to Mr. S. J. ReHFELD for many helpful discussions.

acetate $^{48}$.

\title{
Lumineszenzuntersuchungen zum Problem der Energieübertragung in organischen Molekülkristallen
}

\author{
F. BELITZ \\ I. Physikalisches Institut der Universität Gießen \\ (Z. Naturforsch. 25 a, 955-966 [1970] ; eingegangen am 23. März 1970)
}

\begin{abstract}
From fluorescence spectra and decay times of single crystals of 2.3-dimethylnaphthalene, phenanthrene and p-terphenyl doped with one or two different types of fluorescence molecules (anthracene and, or tetracene) informations about the energy transfer processes are obtained. For doping concentrations smaller than $4 \cdot 10^{-4} \mathrm{Mol} / \mathrm{Mol}$ the transfer by excitons is the main process. The dipole-dipole interaction over distances more than $80 \AA$ (14 mean molecular distances) can be excluded. The mean travelling distance of the excitons in the three host lattices was found to be $250-300$ mean molecular distances.
\end{abstract}

\section{Einleitung}

Zur Untersuchung des Energieübertragungsmechanismus wurden neben polykristallinen Pulvern ${ }^{1-3}$ bereits mehrfach dotierte Einkristalle aromatischer Kohlenwasserstoffe benutzt. Sowohl aus den relativen Intensitäten von Grundgitter- und Gastfluoreszenz ${ }^{4,5}$ als auch aus der Abnahme der GrundgitterAbklingdauer mit steigender Gastkonzentration ${ }^{6-8}$ lassen sich Rückschlüsse auf Art und Reichweite des Energieübertragungsgprozesses ziehen.

Für die Erklärung der Energieübertragung in organischen Molekülkristallen wird meistens die Beschreibungsweise durch Excitonenwellen herangezogen ${ }^{9-11}$. Powell und KePler ${ }^{12}$ schließen allerdings aus Abklingzeitmessungen am System Anthracen/Tetracen auf eine starke Beteiligung einer weitreichenden Dipol-Dipol-Wechselwirkung ${ }^{13}$. Bei geringen Gastkonzentrationen und großen Schichtdicken wird gelegentlich auch eine zusätzliche Ener-

Sonderdruckanforderungen an I. Physikalisches Institut der Universität Gießen, D-6300 Gießen, Leihgesterner Weg 104-108.

1 E. J. Bowen, E. Mikiewicz u. F. W. Smith, Proc. Phys. Soc. London A 62, 26 [1949].

2 W. Hanle u. H. G. Jansen, Z. Naturforsch. 9 a, 791 [1954].

3 A. Schmillen, Z. Physik 150, 123 [1958].

4 K.W. BenZ u. H. C.Wolf, Z. Naturforsch. 19 a, 177 [1964].

5 W. Klöpffer, J. Chem. Phys. 50, 1689 [1969].

6 A. M. Bonch-Bruevich et al., Opt. Spectr. 11, 335 [1961]. gieübertragung durch Emission und Reabsorption von Strahlung beobachtet. Die vorliegende Untersuchung versucht durch Messungen an doppelt dotierten Einkristallen mit Gastkonzentrationen zwischen $10^{-6}$ und $10^{-3} \mathrm{Mol} / \mathrm{Mol}$ weiteren Einblick in diese Frage zu gewinnen.

Die Grundgitter- und Gastsubstanzen wurden so gewählt, daß sich ihre Fluoreszenzspektren mit Hilfe von geeigneten Filterkombinationen trennen lassen. Als Grundgitter wurden die Verbindungen 2,3-Dimethylnaphthalin $(2,3 \mathrm{DN})$, Phenanthren $(\mathrm{Ph})$ und p-Terphenyl (p-Tp) gewählt, als Dotierungen dienten Anthracen (A) und Tetracen (T).

In diesen ternären Systemen kann durch gezielte Anregung der einzelnen Komponenten untersucht werden, ob die beiden Dotierungen ihre Anregungsenergie unabhängig voneinander aus dem Excitonenband des Wirtes beziehen, oder ob auch eine Energieübertragung von der einen zur anderen Gastkomponente stattfindet. Letzterer Prozeß könnte bei

7 A. Schmillen u. J. Kohlmannsperger, Z. Naturforsch. 18 a, 627 [1963].

8 K. Kramer, Z. Naturforsch. 22 a, 1108 [1967].

9 A. S. Davydov, Theory of Molecular Excitons (English Translation), McGraw-Hill Book Co., New York 1962.

10 D. S. McClure, Solid State Phys. 8, 1 [1959].

11 H. C. Wolf, Solid State Phys. 9, 1 [1959].

12 R. C. Powell u. R. G. Kepler, Phys. Rev. Letters 22, 636 [1969].

13 TH. Förster, Fluoreszenz organischer Verbindungen, Vandenhoeck und Ruprecht, Göttingen 1951. 